\title{
Obesity and tooth wear among American adults: the role of sugar-sweetened acidic drinks
}

\author{
Yousaf Kamal $^{1} \cdot$ Saoirse $\mathrm{O}^{\prime}$ Toole $^{1} \cdot$ Eduardo Bernabé $^{1}$ (D)
}

Received: 15 October 2018 / Accepted: 22 September 2019 / Published online: 27 October 2019

(C) The Author(s) 2019

\begin{abstract}
Background To explore the association between obesity and tooth wear among American adults and the role of sugar-sweetened acidic drinks consumption in explaining that association.

Methods We analyzed data from 3541 adult participants in the National Health and Nutrition Examination Survey. Obesity was determined using the body mass index and tooth wear was assessed using the modified tooth wear index. Daily intake of four categories of drinks was estimated as the average (drinks/day) of two consecutive 24-h dietary recalls. The association between obesity and number of surfaces with moderate-to-severe tooth wear was assessed in hurdle models adjusting for sociodemographic factors, acid reflux medication, and dental insurance.

Results Overweight and obese adults had more surfaces with moderate-to-severe tooth wear than those with normal body size, after adjusting for confounders. The consumption of sugar-sweetened acidic drinks explained part, but not all the above association. More specifically, the estimate for obesity was fully attenuated, whereas the estimate for overweight was slightly attenuated but remained significant.

Conclusion Obesity was positively associated with tooth wear in American adults. This association was only partially accounted for by the consumption of sugar-sweetened acidic drinks, a common risk factor for both conditions.

Practical implications Dentists must be aware of the health consequences of sugar-sweetened acidic drinks and advocate for reduction in consumption and/or substitution with healthier alternatives.
\end{abstract}

Keywords Tooth wear $\cdot$ Obesity $\cdot$ Carbonated beverages $\cdot$ Acidic drinks $\cdot$ Adult $\cdot$ Public health dentistry

\section{Introduction}

Tooth wear is the loss of dental hard tissues resulting of the interaction between teeth and other materials (abrasion), tooth-to-tooth contact (attrition), or dissolution of hard tissues by acidic substances not caused by bacteria (erosion) $[1,2]$. As the prevalence of tooth wear is raising [3, 4], a focus on prevention may prolong the health of the dentition. At the

Electronic supplementary material The online version of this article (https://doi.org/10.1007/s00784-019-03079-5) contains supplementary material, which is available to authorized users.

Eduardo Bernabé

eduardo.bernabe@kcl.ac.uk

1 Faculty of Dentistry, Oral \& Craniofacial Sciences, King's College London, Denmark Hill Campus, Bessemer Road, London SE5 9RS UK same time, obesity is increasing at an alarming rate globally to the point it is now considered a global pandemic $[5,6]$.

A few studies have investigated the association between obesity and tooth wear [7-10], with most evidence coming from studies in children [7-9]. However, results are still contradicting as one study in England showed that obese children were more likely to have erosive tooth wear than normal weight children [8], whereas studies in the USA [7] and Brazil [9] reported no association between the two conditions. A study among Swedish young adults found that overweight and obesity were more common among participants with dental erosion than among those with no erosion. However, results were merely descriptive since estimates were not adjusted for potential confounders [10].

There are several potential reasons why obese individuals may be more likely to have tooth wear. First and foremost is the confounding role of factors associated with both obesity and tooth wear. One of those factors is the increased consumption of soft drinks, which is associated with both obesity [11, 
$12]$ and tooth wear $[13,14]$. Globally, a rise in soft drinks consumption $[15,16]$ parallels those in obesity $[5,6]$ and tooth wear $[3,4]$. However, while it is the sugar content of soft drinks (often referred to as sugar-sweetened beverages) what leads to obesity [15], it is the acidic nature of some drinks (such as carbonated drinks and acidic fruit juices) that leads to tooth wear [14]. As such, the key confounder here is the consumption of sugar-sweetened acidic drinks. Beyond the confounding role of sugar-sweetened acidic drinks, it is possible that obesity has an independent effect on tooth wear. Abdominal obesity could be associated with esophageal dysfunction, such as increased acid exposure and reflux symptoms, which in turn may lead to a higher risk of intrinsic erosive tooth wear $[17,18]$. More pathological tooth wear and more vomiting and gastroesophageal reflux has also been observed among morbidly obese adults (waiting for bariatric surgery) than healthy controls [19].

The above factors may be interrelated but have yet to be fully investigated. Therefore, the aim of this study was to explore the association between obesity and tooth wear among American adults and the role of the consumption of sugarsweetened acidic drinks in explaining that association.

\section{Methods}

\section{Data source}

We used data from the National Health and Nutrition Examination Survey (NHANES) 2003-04, which is part of a series of surveys conducted by the Center for Disease Control and Prevention (CDC) to assess the health and nutritional status of the non-institutionalized civilian population aged 2 years and older residing in the USA [20]. The 200304 NHANES is the only survey that included an expanded oral health section providing information on oral health conditions that were never assessed previously and have not been assessed again since then.

The selection of survey participants was conducted by stratified, multistage probability sampling to recruit a representative sample. Oversampling was conducted on certain subgroups which included non-Hispanic blacks, Mexican Americans, and participants aged 12 to 19 years and 60 years or more. Data were collected through phone interviews, faceto-face interviews, and clinical examinations. A total of 10,122 individuals of the eligible population agreed to take part in the survey (79\% response rate). The expanded oral health examination was conducted on participants aged 13 years and older and included 8272 participants $(76 \%)$ [20]. The NHANES 2003-04 survey included 4308 participants aged 18 years and over with complete tooth wear. We excluded 767 participants because of missing data on obesity, dietary data, and confounders. Therefore, the study sample included 3541 participants.

\section{Variables selection}

The outcome variable for this study was tooth wear, which was assessed using the modified tooth wear index (TWI), has been used in the UK Adult Dental Health Survey [21]. The clinical assessment included visual examination of the facial, lingual, and incisal surfaces of the 12 anterior teeth as well as occlusal surfaces of the first molars (40 tooth surfaces overall). Tooth surfaces were scored as sound (any wear restricted to the enamel); mild tooth wear (loss of enamel just exposing dentine); moderate tooth wear (dentine exposure greater than one-third of the surface); or severe tooth wear (complete loss of enamel, pulp exposure, or exposure of secondary dentine). Oral clinical examinations were conducted by two trained and calibrated examiners. Inter-examiner reliability for the tooth wear examination gave a percent agreement of $87.7 \%$ and a kappa of 0.80 [20]. The number of surfaces with moderate-tosevere tooth wear was the outcome for this study.

The exposure was obesity measured using the body mass index (BMI). Trained health technicians measured participants' weight and height using standard protocols and equipment [22]. BMI was calculated as body weight (in kilograms) divided by the square of height (in meters) and used to classify participants as normal (BMI $<25)$, overweight $(25 \leq \mathrm{BMI} \leq 29.9)$, or obese $(\mathrm{BMI} \geq 30)$.

Several confounders were also selected for analysis based on previous studies [23, 24]. A basic set of confounders included demographic characteristics (sex, age, race/ethnicity), socioeconomic position (education and poverty income ratio), acid reflux medication (antacids and anti-reflux medication, as a proxy for gastroesophageal reflux symptoms), and dental insurance coverage. The key confounder in our analysis was the intake of sugar-sweetened acidic drinks, which was estimated from two non-consecutive 24-h recalls [25]. The first 24-h dietary recall was performed in person by trained interviewers in the mobile examination center, while the second 24-h dietary recall was conducted by telephone 3 to 10 days after the examination. Dietary recall data were used to measure an average intake (drinks/day) across the 2 days of four different categories of drinks: sugar-sweetened acidic drinks (SSA: sweetened soda, non-100\% fruit juice, sweetened sports drinks), sugar-sweetened non-acidic drinks (SSNA: sugar-sweetened coffee, tea- and milk-based products with sugar), non-sugar-sweetened acidic drinks (NSSA: diet soft drinks, $100 \%$ fruit juice or flavored sparkling water), nonsugar-sweetened non-acidic drinks (NSSNA: non-sugarsweetened coffee, tea- and milk-based products). The specific USDA food codes included in each of the four categories of drinks are listed in the Appendix. 


\section{Data analysis}

Data were analyzed using Stata/SE version 14.1 (Stata Corp., College Station TX, USA). All analyses were weighted to produce a representative sample and to take account of the variation in cluster size and different sampling rates for clusters within strata.

The distribution of the number of surfaces with moderateto-severe tooth wear was positively skewed, with many participants having zero counts. Therefore, a hurdle model was preferred to model associations with the number of surfaces with moderate-to-severe tooth wear. Hurdle models account for the excessive proportion of zero values and overdispersion [26, 27]. They include two components. The first component estimates the probability of being a non-zero (positive) count from a binary logit model. Odds ratios (OR) were reported for this component of the model, which represent the probability of having moderate-to-severe tooth wear. The second component estimates the mean number of surfaces with moderate-to-severe tooth wear among those with positive counts only (those with tooth wear) using a truncated negative binomial model. Rate ratios (RRs) were reported for this component, which represent how higher/lower the mean number of surfaces with moderate-to-severe tooth wear was in one group compared to the reference group, among those with the condition $[26,27]$.

We first examined the association between each type of drink (SSA, SSNA, NSSA, NSSNA) and the number of surfaces with moderate-to-severe tooth wear through a series of regression models: Model 1A was unadjusted; model 1B was adjusted for confounders (sex, age groups, race/ethnicity, education, poverty income ratio, dental insurance, and acid reflux medication); and model $2 \mathrm{C}$ was additionally adjusted for the remaining types of drinks. We then examined the association between BMI and the number of surfaces with moderate-to-severe tooth wear through a series of regression models: model 2A was unadjusted; model 2B was adjusted for confounders (sex, age groups, race/ethnicity, education, poverty income ratio, dental insurance, and acid reflux medication); models $2 \mathrm{C}$ to $2 \mathrm{~F}$ were additionally adjusted for one type of drink at a time (model 2C: SSA, model 2D: SSNA, model 2E: NSSA, model 2F: NSSNA); and model $3 \mathrm{~F}$ was adjusted for confounders and all four types of drinks simultaneously.

\section{Results}

There were some differences between the study sample and those not included due to missing values on covariates (Table 1). On average, participants in the study sample were older (43.9 versus 39.9 years, $p=0.001$ ) and reported greater consumption of NSSNA drinks (1.51 versus 1.24 drinks/day, $p=0.038)$ than those excluded. In the study sample, the prevalence of moderate-to-severe tooth wear was $12.1 \%$, with an average of 3.4 (95\% confidence interval 2.9-3.9) surfaces affected among those with the condition. Also, $33.7 \%$ and $32 \%$ of adults were overweight and obese, respectively.

The association of the daily intake of different types of drinks with moderate-to-severe tooth wear is presented in Table 2. The intakes of SSA, SSNA, NSSA, and NSSNA drinks were not associated with the probability of having moderate-to-severe tooth wear. However, the intakes of SSA and NSSNA drinks were significantly associated with the number of surfaces with moderate-to-severe tooth wear among those with the condition (model 1B). In those with tooth wear, the number of surfaces affected was 1.40 (95\% CI 1.14-1.73) times higher per additional SSA drink consumed per day. On the other hand, the number of surfaces with moderate-to-severe tooth wear was $17 \%$ (RR $0.83,95 \% \mathrm{CI}$ 0.75-0.93) lower per additional NSSNA drinks consumed per day. These two associations were slightly attenuated but remained significant after further adjustment for other types of drinks (RR of 1.34 and 0.86 for SSA and NSSNA drinks from model $1 \mathrm{C}$, respectively).

BMI was not associated with tooth wear in the unadjusted model (model 2A in Table 3). After adjustment for confounders (model 2B), BMI was not significantly associated with the probability of having moderate-to-severe tooth wear, but it was associated with the number of surfaces with moderate-to-severe tooth wear among those with the condition. In those with tooth wear, the number of surfaces affected was, respectively, 1.72 (95\% CI 1.09-2.71) and 1.61 (95\% CI 1.00-2.58) times higher in overweight and obese adults than in those with normal body size. However, the estimate for obese adults was fully attenuated after further adjustment for either SSA, NSSA, or NSSNA drinks (models 2C, 2E, and 2F, respectively). The estimate for obese adults remained significant after adjustment for SSNA drinks (RR 1.62, 95\% CI 1.01-2.58 from model 2D). When adjusted for confounders and all four types of drinks (model $2 \mathrm{G}$ ), the estimate for overweight remained significant (RR 1.56, 95\% CI 1.04-2.34), while the estimate for obese adults was fully attenuated (RR $1.41,95 \%$ CI $0.90-2.21$ ).

\section{Discussion}

This study first found that obesity was positively associated with tooth wear, independently of known risk factors for tooth wear. Interestingly, this association was found with the number of surfaces with moderate-to-severe tooth wear among those with the condition (i.e., an indication of its severity), but not with the prevalence of tooth wear. Our finding reinforces the opinion that a binary classification of individuals as simply having or not having tooth wear (prevalence) hides 
Table 1 Characteristics of the study sample $(n=3541)$ and comparison with those excluded due to missing data on covariates

\begin{tabular}{|c|c|c|c|c|c|}
\hline \multirow{2}{*}{$\frac{\text { Explanatory variables }}{\text { Sex, } n^{\mathrm{a}} \%}$} & \multicolumn{2}{|c|}{ Excluded } & \multicolumn{2}{|c|}{ Study sample } & \multirow{2}{*}{$\frac{p \text { value }}{0.514}$} \\
\hline & & & & & \\
\hline Men & 162 & 50.5 & 1678 & 48.0 & \\
\hline Women & 177 & 49.5 & 1863 & 52.0 & \\
\hline Age groups, $n^{\mathrm{a}} \%$ & & & & & 0.001 \\
\hline 18-24 years & 109 & 29.7 & 715 & 14.1 & \\
\hline 25-34 years & 44 & 15.0 & 621 & 20.1 & \\
\hline $35-44$ years & 40 & 17.1 & 561 & 19.7 & \\
\hline 45-54 years & 37 & 17.3 & 515 & 20.3 & \\
\hline 55-64 years & 40 & 10.0 & 411 & 12.8 & \\
\hline $65-74$ years & 35 & 6.1 & 392 & 7.8 & \\
\hline $75+$ years & 34 & 4.9 & 326 & 5.2 & \\
\hline Race/ethnicity, $n^{\mathrm{a}} \%$ & & & & & 0.538 \\
\hline White, Non-Hispanic & 166 & 72.8 & 1807 & 72.7 & \\
\hline Black, Non-Hispanic & 82 & 12.4 & 722 & 11.4 & \\
\hline Hispanic & 76 & 9.0 & 882 & 11.4 & \\
\hline Others & 15 & 5.8 & 130 & 4.5 & \\
\hline Education, $n^{\mathrm{a}} \%$ & & & & & 0.200 \\
\hline Less than high school & 102 & 15.4 & 929 & 15.6 & \\
\hline High school & 100 & 32.8 & 885 & 25.2 & \\
\hline More than high school & 134 & 51.9 & 1727 & 59.2 & \\
\hline Poverty income ratio, $n^{\mathrm{a}} \%$ & & & & & 0.059 \\
\hline$<100 \%$ & 49 & 27.8 & 692 & 12.5 & \\
\hline $101-200 \%$ & 48 & 23.8 & 887 & 19.5 & \\
\hline $201-300 \%$ & 21 & 14.5 & 549 & 15.6 & \\
\hline $301-400 \%$ & 16 & 15.4 & 455 & 15.1 & \\
\hline$\geq 401 \%$ & 19 & 18.6 & 958 & 37.4 & \\
\hline Dental insurance, $n^{\mathrm{a}} \%$ & & & & & 0.260 \\
\hline Not covered & 104 & 53.3 & 1762 & 45.9 & \\
\hline Covered & 95 & 46.7 & 1779 & 54.1 & \\
\hline Acid reflux medication, $n^{\mathrm{a}} \%$ & & & & & 0.650 \\
\hline None & 258 & 77.4 & 2724 & 74.2 & \\
\hline Over the counter only & 41 & 14.2 & 505 & 16.3 & \\
\hline Prescribed & 35 & 8.4 & 312 & 9.4 & \\
\hline BMI groups, $n^{\mathrm{a}} \%$ & & & & & 0.542 \\
\hline Normal & 108 & 39.3 & 1189 & 34.5 & \\
\hline Overweight & 93 & 32.8 & 1189 & 33.7 & \\
\hline Obese & 93 & 27.9 & 1163 & 31.9 & \\
\hline SSA drinks, mean (SD) & 0.89 & $(0.94)$ & 0.89 & $(0.97)$ & 0.983 \\
\hline SSNA drinks, mean (SD) & 0.17 & $(0.50)$ & 0.14 & $(0.37)$ & 0.587 \\
\hline NSSA drinks, mean (SD) & 0.29 & $(0.56)$ & 0.38 & $(0.69)$ & 0.089 \\
\hline NSSNA drinks, mean (SD) & 1.24 & $(1.21)$ & 1.51 & $(1.29)$ & 0.038 \\
\hline Surfaces with tooth wear, mean (SD) & 0.38 & $(1.76)$ & 0.41 & $(1.63)$ & 0.700 \\
\hline
\end{tabular}

${ }^{\text {a }}$ Counts are unweighted

SSA, sugar-sweetened acidic drinks; SSNA, sugar-sweetened non-acidic drinks, NSSA, non-sugar-sweetened acidic drinks; NSSNA, non-sugar-sweetened non-acidic drinks; SD, standard deviation fine-grained information on the extent of the condition, and it may potentially mask associations [24].

Beyond this initial finding, we also set up to explore the role of the consumption of SSA drinks in explaining the above association because this category of beverages is associated with both obesity and tooth wear. Therefore, the consumption of SSA drinks may be a common risk factor for both conditions. As expected, SSA drinks consumption was positively 
Table 2 Association between different types of drinks and number of surfaces with moderate-to-severe tooth wear in American adults $(n=$ 3541)

\begin{tabular}{llll}
\hline Model $^{\mathrm{a}}$ & Type of drinks & $\begin{array}{l}\text { Logit portion } \\
\text { OR }[95 \% \text { CI }\end{array}$ & $\begin{array}{l}\text { NB portion } \\
\text { RR }[95 \% \text { CI }]\end{array}$ \\
\hline Model 1A & SSA drinks & $0.68[0.58-0.80]$ & $1.17[0.97-1.41]$ \\
& SSNA drinks & $0.96[0.57-1.61]$ & $1.00[0.71-1.42]$ \\
& NSSA drinks & $1.06[0.87-1.30]$ & $0.94[0.79-1.14]$ \\
& NSSNA drinks & $1.19[1.08-1.31]^{*}$ & $0.95[0.88-1.03]$ \\
Model 1B & SSA drinks & $0.82[0.67-1.01]$ & $1.40[1.14-1.73]^{*}$ \\
& SSNA drinks & $0.97[0.59-1.60]$ & $1.08[0.75-1.57]$ \\
& NSSA drinks & $1.06[0.85-1.34]$ & $1.01[0.79-1.29]$ \\
& NSSNA drinks & $0.92[0.77-1.10]$ & $0.83[0.75-0.93]^{*}$ \\
Model 1C & SSA drinks & $0.79[0.61-1.03]$ & $1.34[1.08-1.66]^{*}$ \\
& SSNA drinks & $0.93[0.56-1.53]$ & $0.96[0.68-1.36]$ \\
& NSSA drinks & $0.98[0.72-1.32]$ & $1.02[0.87-1.20]$ \\
& NSSNA drinks & $0.89[0.74-1.07]$ & $0.86[0.77-0.96]^{*}$ \\
\hline
\end{tabular}

${ }^{\mathrm{a}}$ Model 1A was unadjusted; model 1B was adjusted for sex, age groups, race/ethnicity, education, poverty income ratio, dental insurance, and acid reflux medication; model $1 \mathrm{C}$ was additionally adjusted for the other three categories of drinks

${ }^{\mathrm{b}}$ SSA, sugar-sweetened acidic drinks; SSNA, sugar-sweetened non-acidic drinks; NSSA, non-sugar-sweetened acidic drinks; NSSNA, nonsugar-sweetened non-acidic drinks

${ }^{\mathrm{c}}$ Hurdle regression model was used. Odds ratio (OR) were reported for the logit portion and rate ratios (RR) for the negative binomial (NB) portion. ORs represent the probability of having moderate-to-severe tooth wear in one group compared to the reference group. RRs represent how higher/lower the mean number of surfaces with moderate-to-severe tooth wear is in one group compared to the reference group, among those with the condition

$* p<0.05$

associated with tooth wear and explained part of the association between obesity and tooth wear. Indeed, the estimate for obesity, but not that for overweight, becomes fully attenuated when SSA drinks consumption was included in the regression model. Accounting for other categories of drinks did not alter that finding. It is possible that obese adults have already been diagnosed with the condition and cut down on their usual intake of sugar-sweetened beverages (some of which are acidic). Contrarily, overweight adults might still be indulging in their (high) consumption of SSA drinks. The fact that the association between overweight and tooth wear was not explained away by the intake of SSA drinks implies that other factors may be at play. There is considerable evidence linking obesity with gastroesophageal reflux disease (GERD) symptoms [17, 18], a cause of erosive tooth wear [28, 29]. Increased abdominal pressure caused by central adiposity relaxes the lower esophageal sphincter, thus exposing the esophageal and oral mucosa to gastric content [17]. On the other hand, adipose tissue is metabolically active and induces the production of inflammatory cytokines which may play a role in GERD [18].
Table 3 Models for the association between body mass index (BMI) and number of surfaces with moderate-to-severe tooth wear among American adults $(n=3541)$

\begin{tabular}{|c|c|c|c|}
\hline Model $^{\mathrm{a}}$ & BMI groups & $\begin{array}{l}\text { Logit portion } \\
\text { OR }[95 \% \text { CI] }\end{array}$ & $\begin{array}{l}\text { NB portion }{ }^{b} \\
\text { RR }[95 \% \mathrm{CI}]\end{array}$ \\
\hline \multirow[t]{3}{*}{ Model 2A } & Normal & 1.00 [reference] & 1.00 [reference] \\
\hline & Overweight & $1.09[0.65-1.84]$ & $1.53[0.96-2.45]$ \\
\hline & Obese & $1.12[0.69-1.81]$ & $1.55[0.94-2.57]$ \\
\hline \multirow[t]{3}{*}{ Model 2B } & Normal & 1.00 [reference] & 1.00 [reference] \\
\hline & Overweight & $0.65[0.37-1.15]$ & $1.72[1.09-2.71]^{*}$ \\
\hline & Obese & $0.83[0.51-1.34]$ & $1.61[1.00-2.58]^{*}$ \\
\hline \multirow[t]{3}{*}{ Model 2C } & Normal & 1.00 [reference] & 1.00 [reference] \\
\hline & Overweight & $0.65[0.38-1.13]$ & $1.62[1.09-2.42]^{*}$ \\
\hline & Obese & $0.83[0.52-1.31]$ & $1.54[0.98-2.44]$ \\
\hline \multirow[t]{3}{*}{ Model 2D } & Normal & 1.00 [reference] & 1.00 [reference] \\
\hline & Overweight & $0.65[0.37-1.15]$ & $1.72[1.09-2.70]^{*}$ \\
\hline & Obese & $0.83[0.51-1.34]$ & $1.62[1.01-2.58]^{*}$ \\
\hline \multirow[t]{3}{*}{ Model 2E } & Normal & 1.00 [reference] & 1.00 [reference] \\
\hline & Overweight & $0.65[0.37-1.15]$ & $1.71[1.08-2.71]^{*}$ \\
\hline & Obese & $0.82[0.50-1.34]$ & $1.59[0.99-2.56]$ \\
\hline \multirow[t]{3}{*}{ Model 2F } & Normal & 1.00 [reference] & 1.00 [reference] \\
\hline & Overweight & $0.65[0.36-1.16]$ & $1.63[1.03-2.59]^{*}$ \\
\hline & Obese & $0.81[0.49-1.34]$ & $1.46[0.89-2.37]$ \\
\hline \multirow[t]{3}{*}{ Model 2G } & Normal & 1.00 [reference] & 1.00 [reference] \\
\hline & Overweight & $0.65[0.37-1.15]$ & $1.56[1.04-2.34]^{*}$ \\
\hline & Obese & $0.81[0.49-1.34]$ & $1.41[0.90-2.21]$ \\
\hline
\end{tabular}

${ }^{a}$ Model 2A was unadjusted; model 2B was adjusted for confounders (sex, age groups, race/ethnicity, education, poverty income ratio, dental insurance, and acid reflux medication); model $2 \mathrm{C}$ was adjusted for confounders and sugar-sweetened acidic (SSA) drinks; model 2D was adjusted for confounders and sugar-sweetened non-acidic (SSNA) drinks; model $2 \mathrm{E}$ was adjusted for confounders and non-sugar-sweetened acidic (NSSA) drinks; model 2F was adjusted for confounders and non-sugarsweetened non-acidic (NSSNA) drinks; model $2 \mathrm{G}$ was adjusted for confounders and all four types of drinks

${ }^{\mathrm{b}}$ Hurdle regression model was used. Odds ratio (OR) were reported for the logit portion and rate ratios (RR) for the negative binomial (NB) portion. ORs represent the probability of having moderate-to-severe tooth wear in one group compared to the reference group. RRs represent how higher/lower the mean number of surfaces with moderate-to-severe tooth wear is in one group compared to the reference group, among those with the condition

$* p<0.05$

An additional finding of this study was that the consumption of NSSNA drinks was inversely associated with tooth wear (among those with the condition only), suggesting a potential protective effect. In this study, NSSNA drinks included items like unsweetened tea, coffee, milk, and nonsugar-sweetened milk-based products. Previously, it has been reported that milk-based products were associated with reduced tooth wear [14], although another review reported no association [13]. This protective effect could be due to substitution of the acidic beverage with a less acidic counterpart [14] 
or, less likely, due to the calcium and phosphate levels in the drinks encouraging remineralization or providing sacrificial minerals in the event of an acid challenge [30-32].

The present findings have implications on practice and future research. These results suggest that SSA drinks consumption is a common root for obesity and tooth wear. Addressing their consumption provides an important target area for healthcare practitioners to reduce the health impact of both conditions. It is probably easier to advocate their substitution with NSSNA drinks rather than reducing their consumption all together and recent behavioral research has shown relative success with this method [33]. Further research in this area is needed, and it would be useful to include tooth wear assessment in national health surveys to continue this work. There is also a need for longitudinal studies using multiple dietary assessments, repeated body measurements, and more accurate quantification of tooth wear progression to confirm this relationship.

Some limitations of this study need to be addressed. First, this study was based on cross-sectional data and as such unable to test for causal associations. Second, our study sample represented $82 \%$ of eligible adults, which may raise concerns about representativeness. Since older participants and high-NSSNA drinkers were more likely to be included in the study sample, the present findings should be generalized with caution. Third, tooth wear assessment was based on partial-mouth examination which may not be as valid as full-mouth examination [34]. However, past studies have indicated that anterior teeth and the occlusal surface of first molars are the most commonly affected by tooth wear $[35,36]$. Fourth, we assessed participants' dietary intake through 24 -h recalls, which do not measure long-term dietary habits of individuals and are prone to recall bias and under/over-reporting. Compared with food frequency questionnaire data also available in NHANES, the use of multiple 24-h recalls provided information regarding a significantly larger number of drinks that were combined into four categories. Finally, we were unable to control for GERD (although we used a proxy based on acid reflux medication) or vomiting eating disorders which are known risk factors for tooth wear.

In conclusion, obesity was positively associated with tooth wear in this national sample of American adults. This association was partially accounted for by the consumption of sugarsweetened acidic drinks, a common risk factor for both conditions. All the findings were observed with the extent (among those with the condition) but not the prevalence of moderateto-severe tooth wear.

\section{Compliance with ethical standards}

Conflict of interest The authors declare that they have no conflict of interest.
Ethical approval All procedures performed in studies involving human participants were in accordance with the ethical standards of the institutional and/or national research committee and with the 1964 Helsinki declaration and its later amendments or comparable ethical standards.

Informed consent Written informed consent was obtained from every participant in the study.

Open Access This article is distributed under the terms of the Creative Commons Attribution 4.0 International License (http:// creativecommons.org/licenses/by/4.0/), which permits unrestricted use, distribution, and reproduction in any medium, provided you give appropriate credit to the original author(s) and the source, provide a link to the Creative Commons license, and indicate if changes were made.

\section{References}

1. Shellis RP, Addy M (2014) The interactions between attrition, abrasion and erosion in tooth wear. Monogr Oral Sci 25:32-45. https:// doi.org/10.1159/000359936

2. Carvalho TS, Colon P, Ganss C, Huysmans MC, Lussi A, Schlueter N, Schmalz G et al (2015) Consensus report of the European Federation of Conservative Dentistry: erosive tooth weardiagnosis and management. Clin Oral Investig 19:1557-1561. https://doi.org/10.1007/s00784-015-1511-7

3. Salas MM, Nascimento GG, Huysmans MC, Demarco FF (2015) Estimated prevalence of erosive tooth wear in permanent teeth of children and adolescents: an epidemiological systematic review and meta-regression analysis. J Dent 43:42-50. https://doi.org/10.1016/ j.jdent.2014.10.012

4. Schlueter N, Luka B (2018) Erosive tooth wear - a review on global prevalence and on its prevalence in risk groups. Br Dent J 224:364 370. https://doi.org/10.1038/sj.bdj.2018.167

5. Popkin BM, Adair LS, Ng SW (2012) Global nutrition transition and the pandemic of obesity in developing countries. Nutr Rev 70: 3-21. https://doi.org/10.1111/j.1753-4887.2011.00456.x

6. Ng M, Fleming T, Robinson M, Thomson B, Graetz N, Margono C, Mullany EC et al (2014) Global, regional, and national prevalence of overweight and obesity in children and adults during 1980-2013: a systematic analysis for the Global Burden of Disease Study 2013. Lancet 384:766-781. https://doi.org/10.1016/s0140-6736(14) 60460-8

7. McGuire J, Szabo A, Jackson S, Bradley TG, Okunseri C (2009) Erosive tooth wear among children in the United States: relationship to race/ethnicity and obesity. Int J Paediatr Dent 19:91-98. https://doi.org/10.1111/j.1365-263X.2008.00952.x

8. Tong HJ, Rudolf MC, Muyombwe T, Duggal MS, Balmer R (2014) An investigation into the dental health of children with obesity: an analysis of dental erosion and caries status. Eur Arch Paediatr Dent 15:203-210. https://doi.org/10.1007/s40368-013-0100-1

9. Salas MM, Vargas-Ferreira F, Nascimento GG, Huysmanns MC, Demarco FF (2018) Tooth erosion association with obesity: findings from a Brazilian survey in schoolchildren. Pesquisa Brasileira em Odontopediatria e Clinica Integrada 18:e3764

10. Isaksson H, Birkhed D, Wendt LK, Alm A, Nilsson M, Koch G (2014) Prevalence of dental erosion and association with lifestyle factors in Swedish 20-year olds. Acta Odontol Scand 72:448-457. https://doi.org/10.3109/00016357.2013.859727

11. Trumbo PR, Rivers CR (2014) Systematic review of the evidence for an association between sugar-sweetened beverage consumption and risk of obesity. Nutr Rev 72:566-574. https://doi.org/10.1111/ nure. 12128 
12. Keller A, Bucher Della Torre S (2015) Sugar-sweetened beverages and obesity among children and adolescents: a review of systematic literature reviews. Childhood Obes (Print) 11:338-346. https://doi. org/10.1089/chi.2014.0117

13. Li H, Zou Y, Ding G (2012) Dietary factors associated with dental erosion: a meta-analysis. PLoS One 7:e42626. https://doi.org/10. 1371/journal.pone.0042626

14. Salas MM, Nascimento GG, Vargas-Ferreira F, Tarquinio SB, Huysmans MC, Demarco FF (2015) Diet influenced tooth erosion prevalence in children and adolescents: results of a meta-analysis and meta-regression. J Dent 43:865-875. https://doi.org/10.1016/j. jdent.2015.05.012

15. Popkin BM, Hawkes C (2016) Sweetening of the global diet, particularly beverages: patterns, trends, and policy responses. Lancet Diabetes Endocrinol 4:174-186. https://doi.org/10.1016/s22138587(15)00419-2

16. Dunford EK, Popkin BM (2017) Disparities in snacking trends in US adults over a 35 year period from 1977 to 2012. Nutrients 9:809. https://doi.org/10.3390/nu9080809

17. Friedenberg FK, Xanthopoulos M, Foster GD, Richter JE (2008) The association between gastroesophageal reflux disease and obesity. Am J Gastroenterol 103:2111-2122. https://doi.org/10.1111/j. 1572-0241.2008.01946.x

18. Emerenziani S, Rescio MP, Guarino MP, Cicala M (2013) Gastroesophageal reflux disease and obesity, where is the link? World $\mathrm{J}$ Gastroenterol 19:6536-6539. https://doi.org/10.3748/wjg.v19.i39. 6536

19. Alves MS, da Silva FA, Araujo SG, de Carvalho AC, Santos AM, de Carvalho AL (2012) Tooth wear in patients submitted to bariatric surgery. Braz Dent J 23:160-166. https://doi.org/10.1590/S010364402012000200012

20. Dye BA, Nowjack-Raymer R, Barker LK, Nunn JH, Steele JG, Tan $\mathrm{S}$, Lewis BG et al (2008) Overview and quality assurance for the oral health component of the National Health and Nutrition Examination Survey (NHANES), 2003-04. J Public Health Dent 68:218-226. https://doi.org/10.1111/j.1752-7325.2007.00076.x

21. Li MH, Bernabe E (2016) Tooth wear and quality of life among adults in the United Kingdom. J Dent 55:48-53. https://doi.org/10. 1016/j.jdent.2016.09.013

22. Centers for Disease Control and Prevention (2000) National Health and Nutrition Examination Survey - Anthropometry Procedures Manual. National Center for Health Statistics

23. O'Toole S, Bernabe E, Moazzez R, Bartlett D (2017) Timing of dietary acid intake and erosive tooth wear: a case-control study. J Dent 56:99-104. https://doi.org/10.1016/j.jdent.2016.11.005

24. Al-Zwaylif LH, O'Toole S, Bernabe E (2018) Type and timing of dietary acid intake and tooth wear among American adults. J Public Health Dent. https://doi.org/10.1111/jphd.12264
25. Raper N, Perloff B, Ingwersen L, Steinfeldt L, Anand J (2004) An overview of USDA's dietary intake data system. J Food Compos Anal 17:545-555. https://doi.org/10.1016/j.jfca.2004.02.013

26. Cameron AC, Trivedi PK (2013) Regression analysis of count data. Cambridge University Press, Cambridge

27. Hilbe JM (2014) Modeling count data. Cambridge University Press, Cambridge

28. Moazzez R, Bartlett D (2014) Intrinsic causes of erosion. Monogr Oral Sci 25:180-196. https://doi.org/10.1159/000360369

29. Wilder-Smith CH, Materna A, Martig L, Lussi A (2017) Longitudinal study of gastroesophageal reflux and erosive tooth wear. BMC Gastroenterol 17:113-116. https://doi.org/10.1186/ s12876-017-0670-1

30. Aimutis WR (2004) Bioactive properties of milk proteins with particular focus on anticariogenesis. J Nutr 134:989s-995s. https://doi. org/10.1093/jn/134.4.989S

31. Barbour ME, Shellis RP, Parker DM, Allen GC, Addy M (2008) Inhibition of hydroxyapatite dissolution by whole casein: the effects of $\mathrm{pH}$, protein concentration, calcium, and ionic strength. Eur J Oral Sci 116:473-478. https://doi.org/10.1111/j.1600-0722.2008.00565. $\mathrm{x}$

32. Al-Khateeb SN, Tarazi SJ, Al Maaitah EF, Al-Batayneh OB, Abu Alhaija ES (2014) Does acid etching enhance remineralisation of arrested white spot lesions? Eur Arch Paediatr Dentist 15:413-419. https://doi.org/10.1007/s40368-014-0131-2

33. O'Toole S, Newton T, Moazzez R, Hasan A, Bartlett D (2018) Randomised controlled clinical trial investigating the impact of implementation planning on behaviour related to the diet. Sci Rep 8: 8024-8026. https://doi.org/10.1038/s41598-018-26418-0

34. Ganss C, Young A, Lussi A (2011) Tooth wear and erosion: methodological issues in epidemiological and public health research and the future research agenda. Community Dent Health 28:191-195. https://doi.org/10.1922/CDH_2796Ganss05

35. Steele JG, Walls AW (2000) Using partial recording to assess tooth wear in older adults. Community Dent Oral Epidemiol 28:18-25. https://doi.org/10.1034/j.1600-0528.2000.280103.x

36. Johansson AK, Omar R, Carlsson GE, Johansson A (2012) Dental erosion and its growing importance in clinical practice: from past to present. Int J Dentist 2012:632907. https://doi.org/10.1155/2012/ 632907

Publisher's note Springer Nature remains neutral with regard to jurisdictional claims in published maps and institutional affiliations. 